\title{
Investigation of the composition and causes of membrane fouling of reverse osmosis
}

\author{
Stanislav Saitov ${ }^{1 *}$, and Natalia Chichirova ${ }^{1}$ \\ ${ }^{1}$ Kazan state power engineering university, Thermal power plants Department, 420066 Kazan, Russia
}

\begin{abstract}
The report shows the results of investigation of the composition of fouling formed during Sheshma river water softening reverse osmosis filter. A research technique is disclosed, which includes energy dispersive spectroscopy and ATR FTIR spectroscopy, atomic force microscopy and scanning electron microscopy. An analysis of the causes of membrane fouling is carried out, the effectiveness of chemical pre-treatment is evaluated.
\end{abstract}

\section{Introduction}

Throughout the world, membrane water treatment technologies are widely used in various industries, including in the energy sector.

In the Russian Federation, this technology appeared relatively recently - in the second half of the $2000 \mathrm{~s}$, and since then continues to gain popularity [1].

Today, most of the newly commissioned CCGT units and industrial boiler rooms are equipped with modern ultrafiltration (UF) and reverse osmosis (RO) units [1]. Their modular design and high automation allow them to successfully fit into the structure of a modern energy enterprise.

However, in case of improper pre-treatment and / or incorrect water-chemical mode, these units are inefficient - the filtrate consumption is reduced, the energy consumption for pump drive is increased, and the manufacturer's guaranteed service life of filtration modules due to membrane fouling is sharply reduced.

Abroad, this problem has been successfully solved for decades. In Russia, membrane fouling remains the main obstacle to the stable and economical operation of membrane water treatment plants (WTP).

The purpose of this investigation is to develop a method (procedure) for diagnosing the causes of UF and RO membrane fouling and testing it at an existing energy facility.

\section{Testing procedure for diagnosing}

\subsection{Material and methods}

Testing of the developed research method was carried out on the spent reverse osmosis module NanoRO K 8040-C, previously used to soften the Sheshma river water of the Kuwak water intake. The module was used as part of the WTP of the Ashalchi industrial boiler house of "TeploEnergo-Service" LLC. The quality indicators of the feed water and water on the steps of the WTP are given in Table 1.

Table 1. The chemical composition of the Sheshma river water along the steps of the Ashalchi boiler house water treatment plant (April, 2019).

\begin{tabular}{|c|c|c|c|}
\hline Indicator & $\begin{array}{c}\text { Feed } \\
\text { water }\end{array}$ & $\begin{array}{c}\text { Clarified } \\
\text { water } \\
\text { (after UF) }\end{array}$ & $\begin{array}{c}\text { Softened } \\
\text { water } \\
\text { (after RO) }\end{array}$ \\
\hline $\mathrm{t},{ }^{\circ} \mathrm{C}$ & +9 & $+28,75$ & $+28,32$ \\
\hline $\mathrm{pH}$ & 8,28 & 7,26 & 5,77 \\
\hline $\mathrm{Cl}^{-}, \mathrm{mg} / \mathrm{L}$ & 220 & 209,5 & 4 \\
\hline $\mathrm{Fe}^{2+}, \mathrm{mg} / \mathrm{L}$ & 156,25 & 59,06 & 3,75 \\
\hline $\mathrm{Al}^{3+}, \mathrm{mg} / \mathrm{L}$ & 85,07 & 86,19 & - \\
\hline $\mathrm{SO}_{4}{ }^{2-}, \mathrm{mg} / \mathrm{L}$ & 106,16 & 117,98 & 1,23 \\
\hline $\mathrm{SiO}_{3}{ }^{2-}, \mathrm{mg} / \mathrm{L}$ & 9,55 & 9,2 & 0,152 \\
\hline $\mathrm{Na}^{+}, \mathrm{mg} / \mathrm{L}$ & - & - & 3100 \\
\hline $\mathrm{PO}_{4}{ }^{3-}, \mathrm{mg} / \mathrm{L}$ & - & - & 6,55 \\
\hline Hardness, mEq/L & 10,5 & 9,67 & 0,11 \\
\hline Alkalinity, mEq/L & 5,2 & 3,2 & 0,08 \\
\hline $\mathrm{COD}, \mathrm{mg} \mathrm{O}_{2} / \mathrm{L}$ & 6,6 & 3,37 & 0,55 \\
\hline $\begin{array}{c}\text { Suspended } \\
\text { solids, mg/L }\end{array}$ & 8,6 & 4,8 & - \\
\hline $\begin{array}{l}\text { Petrochemicals, } \\
\mathrm{mg} / \mathrm{L}\end{array}$ & 0,15 & 0,038 & - \\
\hline
\end{tabular}

The module in question was prematurely decommissioned due to membrane fouling. An autopsy was performed to study the fouling on the membrane surface. To do this, using an angle grinder, the end parts of the element were sawn off, and the fiberglass body was cut along the length. The membrane package

\footnotetext{
$\overline{\text { * Corresponding author: caapel@mail.ru }}$
} 
removed from the body contained 21 polyamide membranes wound around a perforated tube. Samples for research were selected from 5 points along the length of 1,10 and 21 membrane layers (15 pcs). Sizes of the samples are 10-20 $\mathrm{mm}$.

Preliminary preparations samples included:

- Soaking 5 samples (along the length of the module, layer 1) in a $4 \%$ citric acid solution and $1 \%$ acetic acid solution for 15 hours to obtain acid extracts;

- Soaking 5 samples (along the length of the module, layer 21 ) in a $4 \%$ sodium hydroxide solution for 15 hours to obtain salt extracts;

- Soaking 2 samples (at the inlet and outlet of the element, layer 10) in the distillate for subsequent studies with a scanning electron microscope. form.

The remaining samples were investigated in dry

The samples were studied by energy dispersive spectroscopy (EDS) and attenuated total reflectance Fourier transform infrared (ATR FTIR) spectroscopy, scanning electron microscopy (SEM) and atomic force microscopy (AFM).

\subsection{Experimental research}

\subsubsection{SEM}

Using a Quanta200 scanning microscope, a dense adsorption-hydrated layer of high molecular weight organic compounds was detected - the dark areas in the Figure 1 that were uniformly distributed throughout the entire membrane packet. Light spots on the scan correspond to deposits of carbonate and / or calcium sulphate.

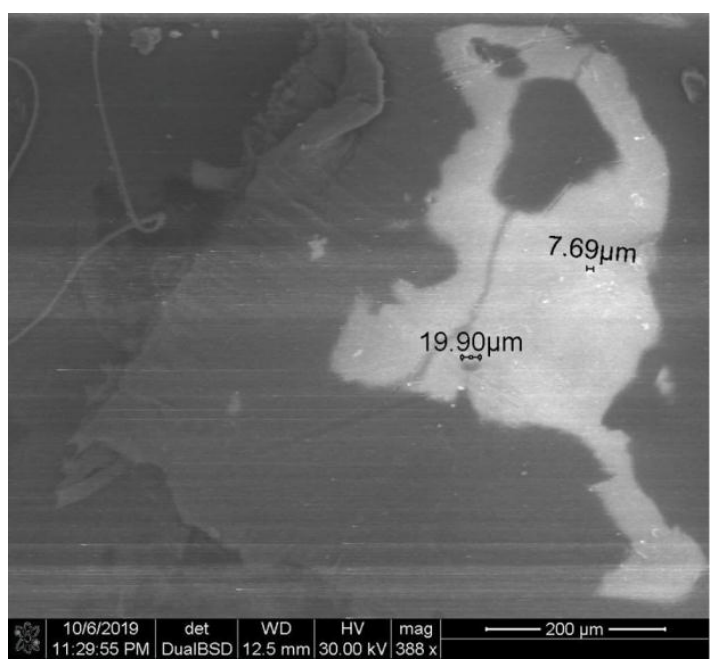

Fig. 1. SEM-scan of the test sample.

\subsubsection{AFM}

AFM scanning using a Solver HV probe microscope showed that membrane fouling proceeds in the direction of movement of the stream being cleaned (Fig. 2, 3). This happens due to an increase in the concentration of dissolved substances in the purified water as it passes through the membrane module. At certain $\mathrm{pH}$, ionic strength and temperature of the solution, the concentration of one or more dissolved substances may exceed their solubility limit. As a result, mineral precipitation occurs on the membrane surface.

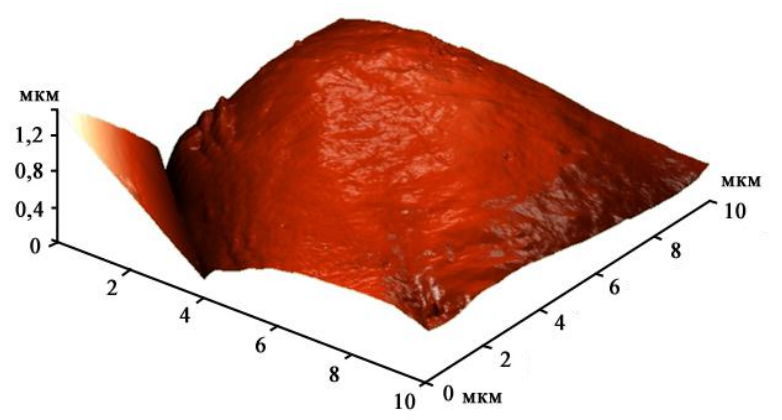

Fig. 2. The morphology of the membrane surface (input module).

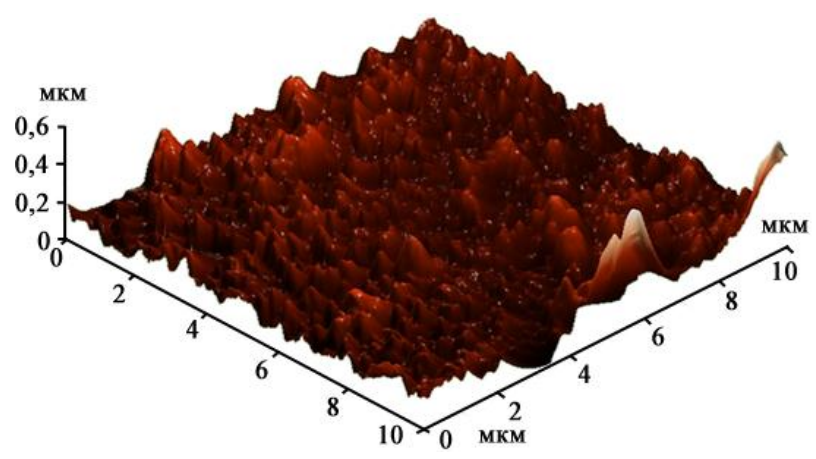

Fig. 3. The morphology of the membrane surface (output module).

\subsubsection{EDS}

According to the Table 2, the main components of inorganic fouling are sulfates, chlorides, phosphates, titanium dioxide, calcium cations.

Table 2. Table 2. Mass fraction (\%) of inorganic components of membrane fouling.

\begin{tabular}{|c|c|c|c|}
\hline $\begin{array}{c}\text { Oxides / } \\
\text { elements }\end{array}$ & $\begin{array}{c}\text { Sample at the } \\
\text { entrance }\end{array}$ & $\begin{array}{c}\text { Sample at } \\
\text { the centre }\end{array}$ & $\begin{array}{c}\text { Sample at } \\
\text { the exit }\end{array}$ \\
\hline \multicolumn{5}{|c|}{ Main components } \\
\hline $\mathrm{SO}_{3} / \mathrm{S}_{\mathrm{x}}$ & $91,02 / 36,44$ & $93,91 / 37,6$ & $94,8 / 37,96$ \\
\hline $\mathrm{Cl} / \mathrm{Cl}$ & $3,48 / 3,48$ & $1,52 / 1,52$ & $1,68 / 1,68$ \\
\hline $\mathrm{TiO} / \mathrm{Ti}$ & $2,23 / 1,34$ & $3,24 / 1,94$ & $2,35 / 1,41$ \\
\hline $\mathrm{P}_{2} \mathrm{O}_{5} / \mathrm{P}_{\mathrm{x}}$ & $0,94 / 0,41$ & $0,95 / 0,41$ & $0,74 / 0,32$ \\
\hline $\mathrm{CaO}_{\mathrm{Na}}$ & $0,763 / 0,546$ & $0,271 / 0,194$ & $0,237 / 0,17$ \\
\hline \multicolumn{5}{|c|}{ Trace impurities } \\
\hline $\mathrm{K}_{2} \mathrm{O} / \mathrm{K}$ & $0,339 / 0,281$ & $0,0497 / 0,0413$ & $0,15 / 0,124$ \\
\hline $\mathrm{Fe}_{2} \mathrm{O}_{3} / \mathrm{Fe}$ & $0,0305 / 0,0213$ & $0,0201 / 0,0141$ & $0,0069 / 0,0048$ \\
\hline $\mathrm{ZnO}_{2} / \mathrm{Zn}$ & $0,0178 / 0,0143$ & $0,0199 / 0,0160$ & $0,0197 / 0,0158$ \\
\hline $\mathrm{Sb}_{2} \mathrm{O}_{3} / \mathrm{Sb}$ & $0,0103 / 0,0086$ & $0,0126 / 0,0105$ & $0,01 / 0,0084$ \\
\hline
\end{tabular}




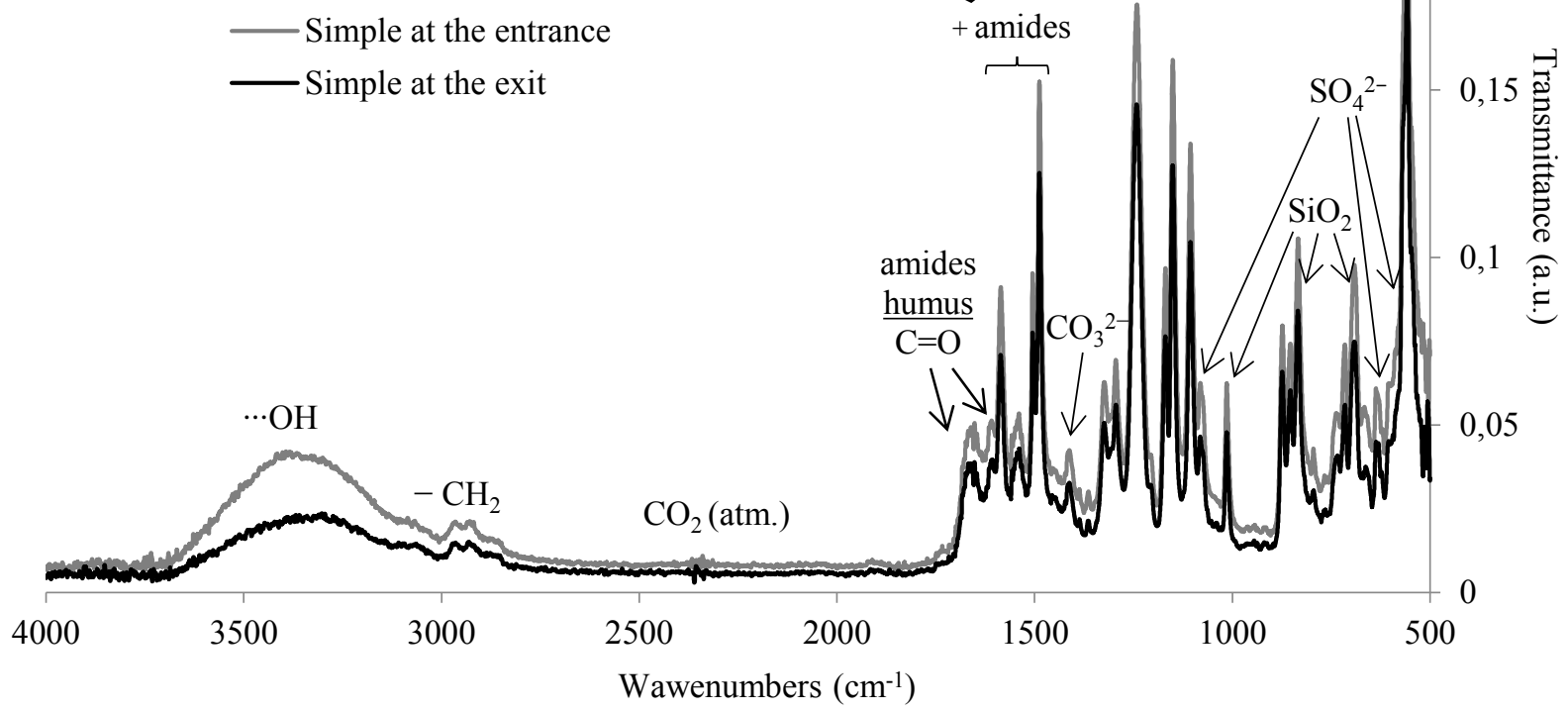

Fig. 4. Combined FTIR spectra of samples of polyamide membranes at the entrance and exit of the membrane module.

In trace amounts $(<0,1 \%)$, potassium, iron, zinc and antimony were also found. These components were not taken into account.

\subsubsection{ATR FTIR}

An analysis of the infrared spectrum (Fig. 4), recorded on an Alpha (Bruker Optics) FTIR spectrometer by the method of impaired attenuated total reflection (ATR), showed that a set of functional groups corresponding to the IR absorption ranges is humic compounds (mainly humic and fulvic acids), sulfates, and, to a small extent, carbonates.

\section{Results and discussion}

Analysis of the experimental data obtained during the study showed that the main components of membrane fouling are:

- Organic (humic) compounds, including colloidal FeO: $56-58 \%$,

- Anions of strong acids $\left(\mathrm{Cl}^{-}, \mathrm{SO}_{4}{ }^{2-}\right): 39-40 \%$,

- Silicates $\left(\mathrm{SiO}_{2}\right): 0,8-4,2$,

- Phosphates $\left(\mathrm{PO}_{4}{ }^{3-}\right)$ : 0,75-0,95\%,

- and, to a lesser extent, $\mathrm{CaO}$ (in the form of carbonates): up to $0,763 \%$.

The results obtained are completely consistent with the data on the chemical composition of the feed water (Table 1) and do not contradict each other.

The presence of titanium dioxide $\left(\mathrm{TiO}_{2}\right)$ in the composition of inorganic components (Table 2) is explained by its use in the manufacture of membranes [2-5].
The cause of humus fouling is acidic water-chemical mode of WTP. The removal of organic matter at the pretreatment stage occurs only partially (decrease COD by $50 \%$, Table 1), as a result of which it appears in clarified water. Usually, natural organic matterials (NOM), such as humic and fulvic acids, at near-neutral $\mathrm{pH}$ values $(7,0 \div 8,0)$ are negatively charged due to the ionization of $\mathrm{COOH}$ and phenolic $\mathrm{OH}$-groups. At low $\mathrm{pH}(5,0 \div 6,5)$, these functional groups are protonated, resulting in the adsorption of humic compounds into the porous membrane structure [6].

The deposition of phosphates is associated with the dosing of phosphate-containing inhibitors (Aquaresult ${ }^{\mathrm{TM}}$ 1030 and Aminat ${ }^{\mathrm{TM}} \mathrm{K}$ ) in clarified water [7]. Their presence was also recorded in softened water (Table 1).

The presence of chlorides and sulfates is explained by the fact that the cationic surface of the polyamide membrane serves as a counterion for $\mathrm{Cl}^{-}$and $\mathrm{SO}_{4}{ }^{2-}$. To prevent chemisorption of strong acid anions by amide groups, it is necessary to reduce the surface charge (or $\zeta$-potential) of the membrane using special detergents (for example, EDTA-Na $\mathrm{N}_{2}$ [8].

It follows that in the considered example, the main causes of membrane fouling are the incorrect (acid) water-chemical mode and the inappropriate set of applied chemicals.

\section{Conclusions}

The developed procedure for the diagnosis of membrane water treatment systems for the presence, composition and causes of membrane fouling can be scaled to various plants, enterprises, and water sources, which allows, in the future, more efficiently debug the water-chemical 
mode of membrane water treatment systems at the initial stages of operation of energy enterprises .

\section{References}

1. N. Chichirova, A. Chichirov, A. Filimonova, S. Saitov, Therm. Eng. 64, 12 (2017)

2. Y. Wei, H.Q. Chu, B.Z. Dong, X. Li, S.J. Xia, Z.M. Qiang, Desalination 272, 90-97 (2011)

3. J.H. Li, Y.Y. Xu, J.H. Li, L.P. Zhu, J.H. Wang, C.H. Du, J. Membr. Sci. 326, 659-666 (2009)

4. S.J. Oh, N. Kim, Y.T. Lee, J. Membr. Sci. 345, 13-20 (2009)

5. L.Y. Yu, H.M. Shen, Z.L. Xu, J. Appl. Polym. Sci., 113, 1763-1772 (2009)

6. Y. Shim, H.J. Lee, S. Lee, S.H. Moon, J. Cho, Environ. Sci. Technol. 36, 3864-3871 (2002)

7. J. Gabelich, R. Chen, I. Yun, M. Coffey, I.H. Suffet, Desalination 180, 307-319 (2005)

8. A. Weis, M.R. Bird, M. Nyström, J. Membr. Sci. 516, 67-79 (2003) 